\title{
Promoting Resilience and Agency in Children and Young People Who Have Experienced Domestic Violence and Abuse: the "MPOWER" Intervention
}

\author{
Jane E. M. Callaghan ${ }^{1}$ (D) $\cdot$ Lisa C. Fellin ${ }^{2} \cdot$ Joanne H. Alexander $^{3}$ \\ Published online: 6 December 2018 \\ (C) The Author(s) 2018
}

\begin{abstract}
The MPOWER programme is a resource oriented intervention to support children and young people (CYP) affected by domestic violence and abuse. It draws on principles from feminist informed systemic family practice and creative therapies. The intervention was delivered in 4 European countries (Greece, Italy, Spain and England), reaching 58 CYP. This paper reports on young participants' wellbeing outcomes and perceptions of the intervention. Participants completed the Children's Outcome Rating Scale, and the Children's Group Session Rating Scale (Duncan et al. Journal of Brief Therapy, 3, 3-12, 2003). A descriptive analysis of this data suggests improvement in subjective wellbeing as CYP moved through this programme. Qualitative interviews were also conducted with $21 \mathrm{CYP}$, exploring their experience of the group intervention and of its impact. These interviews were analysed thematically (Braun and Clark Qualitative Research in Psychology, 3(2), 77-101, 2006). Three themes are discussed: These were "Working Together: Building Trust and Sharing Common Experiences"; "Disclosures, creativity and working with emotions"; and "Roots and Branches: Working with relationships".
\end{abstract}

Keywords Domestic violence Intimate partner violence $\cdot$ Children · Routine outcomes monitoring $\cdot$ Group intervention · Resilience $\cdot$ Agency $\cdot$ MPOWER

Children and young people (CYP) who live with domestic violence and abuse are at higher risk for the development of mental health difficulties (Fergusson et al. 2005; Fujiwara et al. 2012; Hunt et al. 2017; McFarlane et al. 2017; Meltzer et al. 2009), as well as a range of other negative psychosocial and economic outcomes (Wood and Sommers 2011). Despite clear evidence of mental health need amongst this group of CYP, very few have access to appropriate mental health interventions (CAADA 2014).

One of the reasons for lack of access to services to help CYP heal after domestic violence and abuse is a lack of clear evidence base for the effectiveness of interventions, as few

Jane E. M. Callaghan

jane.callaghan@stir.ac.uk

1 Centre for Child Wellbeing and Protection, University of Stirling, Stirling FK9 4LA, UK

2 Department of Psychology, University of East London, London, UK

3 Institute of Public Safety, Crime and Justice, University of Northampton, Northampton, UK good rigorous trials have been conducted (Howarth et al. 2016). The limited evidence we do have suggests that good quality, group based interventions can make a difference in CYP's resilience and wellbeing after domestic violence and abuse (Jenney and Alaggia 2012). Group interventions that are available focus on CYP's relationships with non-violent parents (Bunston et al. 2016; Smith 2016), emotional literacy (Lacasa et al. 2016), disrupted attachments and trauma (Bunston et al. 2016), and the prevention of involvement in future violence and abuse (Cornelius and Resseguie 2007; Siegel 2013). Some interventions focus on processing the violence itself (Glodich and Allen 1998; Peled and Davis 1995; Roseby et al. 2005; Tjersland 2012). Only a small number of documented programmes offer a strengths-based approach, but these are not widely reported in peer reviewed literature (e.g. see the report provided by Campo et al. 2014, for a review of these). In Europe, the most widely used group based interventions are mother-and-child based. For example, the CEDAR (Children Experiencing Domestic Abuse Recovery) programme in Scotland (Sharp et al. 2011), the DART programme (Domestic Abuse Recovery Together) in England and Wales (Smith 2016), 
and "Talking to My Mum" (Humphreys 2006) are psychoeducational group based programmes that focus on rebuilding the mother-child relationship (typically undermined by domestic abuse), helping mothers and children understand the impact of domestic abuse, support children in appropriate emotional expression, safety planning, and building self-esteem. These important groups provide much needed support for mother-child relationships, and take a strengths based approach.

This article adds to the literature on group based interventions, through an evaluation of a strengths based and systemically informed group programme, for CYP - the MPOWER programme. The MPOWER intervention differs somewhat from previous programmes in that it takes a broader relational focus, exploring the implications of domestic abuse for children's wider social network. Our approach also frames 'strengths' or resilience systemically, exploring how relationships function to strengthen or challenge CYP's sense of wellbeing, Our work frames resilience as a multifaceted process that CYP navigate in an active and engaged way, in a social and relational context (Zahradnik et al. 2009; Ungar 2011). Following Walsh's $(2015,2003)$ systemic model, we suggest that resilience is rooted in family and relational functioning, linked to family belief systems, ways of organising familial and other relational patterns, and patterns of communication and problem solving within the CYP's relational network. Resilience is located in CYPs experiences and stories, rather than being understood as an individual characteristic, as it is in a more traditional psychological formulation of resilience (e.g. Masten et al. 2009; Peterson and Yates 2013). We suggest CYP's resilience is constituted through their capacity for agency and their ability to construct a resilient sense of self in relation to the violent, coercive and controlling dynamics of their family life. This article explores how CYP experienced the MPOWER intervention, and whether CYP reported perceived benefit in the intervention's focus on the strengths they developed to cope with domestic violence and abuse (Callaghan et al. 2016a, b, 2017a, b), and that built on their capacity for resistance and agency.

\section{The MPOWER Intervention}

The MPOWER intervention was developed as part of the second phase of an action research project, Understanding Agency and Resistance Strategies. In the first phase we interviewed 107 CYP across four countries (Greece, Italy, Spain and England, UK) about their experiences of domestic abuse and how they coped with it. In these interviews CYP told us that they maintained a sense of agency, and a capacity for resistance in a range of ways: by maintaining caring relationships (Callaghan et al. 2016b); by using space and their material environment to keep themselves and others safe
(Callaghan et al. 2016a); through the ways they found to manage complex emotion (Callaghan et al. 2017a); by maintaining a sense of their own creativity and playfulness (Fellin et al. 2018b); and by the decisions that they made about how and who to tell about their experiences (Callaghan et al. 2017b). Based on this learning about how children coped, we built a group based therapeutic intervention, the "MPOWER" programme, focused on developing and building on CYP's strengths. It was piloted in England and then implemented with 58 CYP across Italy, Greece, Spain and England. In 2014-2015, this programme was delivered to 58 CYP, in the four participating countries. Building on our research findings in the first phase of the project, the main objective of our intervention was to empower CYP to: build a sense of safety; develop trust in themselves and others; explore, share and develop coping strategies; build positive self-identity and envisage a positive potential future; challenge myths and selffulfilling prophecies about domestic violence; foster caring relationships and social support; and deal with endings and loss.

The MPOWER intervention focused on building the strengths and skills CYP develop when they experience domestic violence and abuse. In this sense, the intervention is based on a presumption of competence, not deficit. Our work with CYP facilitated an understanding of the creative adaptations that they made to enable them to live with the violence and coercive control that they experienced at home. We worked with them in groups to understand how these adaptations developed in context, how these strengths and resistances worked for them, as well as understanding how they might adapt or transform these to support their relationships in non-violent contexts and to manage conflict and challenging emotions better. Although CYP did talk about the violence in their lives, the focus of the intervention was not on the violence itself, but on the effects they experienced in everyday life. This included its relational implications, and its influence CYP's caring / emotional labour, and their coping strategies.

The intervention integrated a narrative systemic approach, that was sensitive to interpersonal relationships and to the social and physical worlds CYP live (White 2004; White and Morgan 2006). It incorporated creative therapeutic methods to support CYP in articulating experiences that might be difficult to voice, like emotions, embodied experience and the relational-material context of home (Perry 2014). The intervention was built around 5 key principles. Principle 1: Making sense of violence and coping focused on identifying and amplifying existing coping and resiliencies, to better understand the meaning of CYP's responses to violence. Principle 2: Violence happens in a physical and relational world involved opening up a space in which CYP could understand the relationally and materially located nature of violence and coercive control, seeing violence and responses to violence in a relational, contextual and embodied way. 
Principle 3: Coping, resistance and resilience as creative experiences emphasized CYP's capacity for creative adaptations to adverse experiences, and worked directly with that creativity through techniques like dance, music, drawing, storytelling and drama, that enabled CYP to explore emotions and relationships as embodied experiences. Principle 4: A resource focused approach meant that facilitators explicitly avoided deficit labelling and pathologizing of CYP's experiences, emphasizing their resources, skills and capacities, not their 'symptoms' or mental health 'diagnoses'. This focus resisted the positioning of CYP as passive victims of domestic violence and abuse, instead supporting the recognition of the multiple ways that they adapted to and coped with violence and coercion, and enabled them to consider the potential a sense of self that was not wounded, damaged, or doomed to repeat cycles of violence. Principle 5: An emotion focused and relational approach meant that facilitators focused on how CYP had experienced emotion in the past, and how emotions were lived in a relational and embodied context. Facilitators worked together with participants to understand their emotional responses to violence and family relationships, what they did with those emotions, and how well their strategies worked. They would experiment with these emotional coping responses, and work together to refine, adapt and transform them.

The programme was arranged around six sessional themes, each with multiple activities that CYP could do (See Fig. 1). The first two sessions focused on trust-building, and the final two sessions on consolidating the group experience, thinking about the future, and closing the experience of the group together. The CYP moved fluidly through the other sessional themes, and throughout the programme there was a focus on creativity, emotion, coping / resources, relationality and embodiment / movement.

The intervention was in a group format, to reduce CYP's sense of isolation and their experience of being 'different' (Stanley et al. 2012). Although the programme offered some guidance on session content and on suggested structured activities, the intervention was CYP centred, with CYP making decisions at the beginning of each session about what they would focus on that day. The wide range of creative and systemically informed activities supported CYP to build a sense of safety and trust in self and in others. This was a central concern for CYP whose trust had been impacted by dishonest, manipulative and controlling family dynamics. Activities also enabled CYP to share their coping strategies, consider what

Fig. 1 The session themes of the MPOWER programme

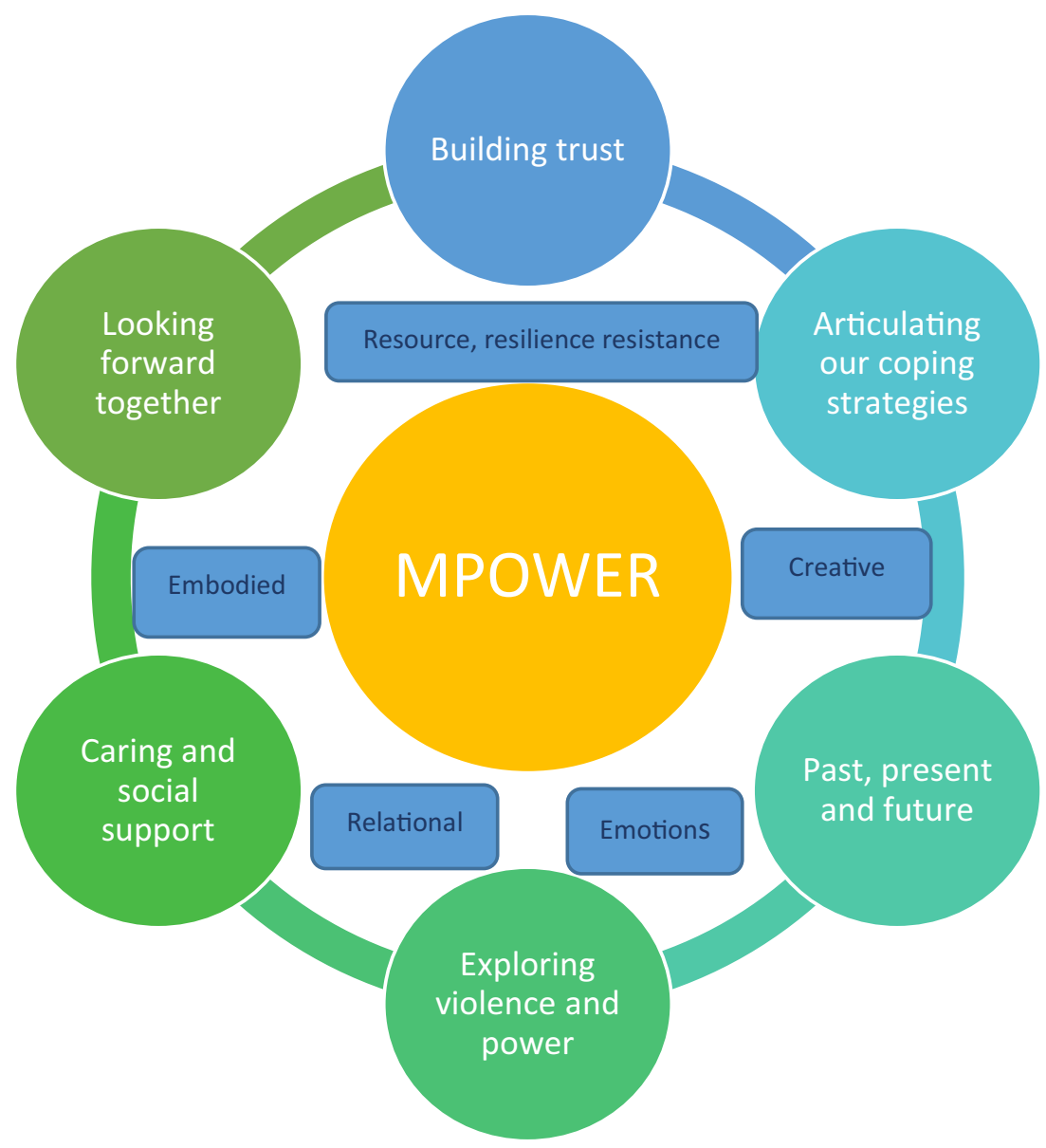


was effective, and explore possible transformations to those coping strategies. This enabled CYP both to discuss their own creative adaptations to living with violence, and to support other CYP. It also created a space within which their own capacity to cope and to resist could be acknowledged and accepted. A common concern in the groups was CYP fear about intergenerational transmission, and CYP spent a lot of group time discussing and challenging myths and self-fulfilling prophecies about DVA. The systemic focus of the group enabled CYP to explore relational dynamics and to think through their own experiences and understandings of caring relationships. Within the group they were also able to experience and share caring relationships with each other, and to offer and experience support. It was our aim through the group to offer a foundation on which CYP could build a more positive sense of self, and of self-in-relationship, could recognize their own skills and capabilities, and could begin to envisage a positive potential future for themselves. For a fuller description of the rationale, principles and intervention structure, see Fellin et al. 2018a.

Most referrals to the programme came from child protection services and refuge workers, with a small number coming from psychology services (3), lawyers (2) and teachers (3). 58 children and CYP took part in the intervention, 28 girls, and 30 boys. Referrers / non-violent parents reported that each CYP had directly seen or experienced multiple episodes of violence at home, and they were referred because professionals felt they would benefit from group work. Most CYP had shown symptoms of psychological distress, but were not receiving mental health support. Each potential participant and their non-violent parent / carer had an induction and assessment interview with the group facilitator, before the group started. CYP were admitted to the group if they were considered to be in a safe situation, and if they felt that they wanted to participate based on the information they were given about the group. Participants ranged in age from 11 to 19 years, with an average age of 15.97. All participants were in a safe place at the time of the intervention, with most living either in refuge, a safe home with their mother or, in Greece, in residential care. Most CYP who joined the intervention attended 6-7 sessions, and drop-out rates were low (of the 62 young people who started the programme, 4 dropped out during the first two taster sessions, but there were only 3 further dropouts across the remainder of the programmes (5\% of the 58 who committed to the programme) (See Table 1). Each intervention group ran for 10 sessions in total, and each group had 2 facilitators. Facilitators came from a range of backgrounds, and included psychology trainees, a play therapist, a clinical psychologist, domestic abuse support workers, and social workers. Sessions ran for 90-120 min.

\section{Method}

The intervention was evaluated using a mixed method design, incorporating session by session ratings of subjective wellbeing and perceptions of the group process, and semi-structured interviews with a subset of the participants.

Table 1 Young people who participated in the intervention

\begin{tabular}{|c|c|c|c|c|c|c|c|c|c|}
\hline Country & $\begin{array}{l}\text { Group } \\
\text { number }\end{array}$ & $\begin{array}{l}\text { Number } \\
\text { of CYP }\end{array}$ & Gender & $\begin{array}{l}\text { Age } \\
\text { range }\end{array}$ & $\begin{array}{l}\text { Mean } \\
\text { age }\end{array}$ & $\begin{array}{l}\text { Sessions attended } \\
(\text { range })^{\mathrm{a}}\end{array}$ & $\begin{array}{l}\text { Mean sessions } \\
\text { attended }^{\text {a }}\end{array}$ & $\begin{array}{l}\text { Dropout } \\
\text { after S2 }\end{array}$ & $\begin{array}{l}\text { Only attended } \\
\text { S1-2 }\end{array}$ \\
\hline Spain & $\mathrm{S} 1$ & 9 & $\begin{array}{l}5 \mathrm{~F} \\
4 \mathrm{M}\end{array}$ & $11-17$ & 13.56 & $6-7$ & 6.89 & 0 & 0 \\
\hline Greece & G1 & 9 & $\begin{array}{l}5 \mathrm{~F} \\
4 \mathrm{M}\end{array}$ & $12-17$ & 13 & $6-10$ & 8.63 & 1 & 0 \\
\hline Greece & G2 & 8 & $\begin{array}{l}6 \mathrm{~F} \\
2 \mathrm{M}\end{array}$ & $15-17$ & 16.13 & $7-10$ & 8.4 & 1 & 1 \\
\hline Greece & G3 & 8 & $8 \mathrm{M}$ & $12-14$ & 12.25 & $6-8$ & 7.375 & 0 & 0 \\
\hline UK & UK1 & 6 & $\begin{array}{l}3 \mathrm{~F} \\
3 \mathrm{M}\end{array}$ & $11-13$ & 11.83 & $3-10$ & 7.67 & 0 & 1 \\
\hline UK & UK2 & 5 & $\begin{array}{l}3 \mathrm{~F} \\
2 \mathrm{M}\end{array}$ & $15-17$ & 16.2 & $9-10$ & 8.5 & 1 & 1 \\
\hline Italy & IT1 & 6 & $\begin{array}{l}4 \mathrm{~F} \\
2 \mathrm{M}\end{array}$ & $18-19$ & 18.67 & 10 & 10 & 0 & 1 \\
\hline Italy & IT2 & 7 & $\begin{array}{l}2 \mathrm{~F} \\
5 \mathrm{M}\end{array}$ & $11-16$ & 12.86 & 10 & 10 & 0 & 0 \\
\hline Totals & & 62 & $\begin{array}{l}28 \mathrm{~F} \\
30 \mathrm{M}\end{array}$ & & 15.97 & & 7.96 & 3 & 4 \\
\hline
\end{tabular}

${ }^{a}$ Mean does not include data for young people who dropped out after the first or second session 


\section{Outcomes Monitoring}

Children who participated in the therapeutic intervention were invited to also take part in the evaluation of the intervention. It was made clear to CYP that their participation in the research would not impact on their access to the intervention or other support. Children who consented completed two routine outcomes measures - one tracking individual outcomes on a session by session basis (the Children's Outcome Rating Scale, CORS) and a session rating scale evaluating their experience of the group (the Children's Group Session Rating Scale, CGSRS) (Duncan et al. 2003). The Children's Outcome Rating Scale provides an accessible measure of children's experience of their levels of personal distress, interpersonal wellbeing, social role and overall wellbeing. The Children's Group Session Rating Scale provides a session by session measure of children's perception of the group process, focused on their experience of mutual respect and understanding, relevance of goals and topics, their sense of 'fit' to the group and to the practitioner, and their overall sense of the group alliance. CYP completed routine outcomes monitoring before the first session, and at each subsequent session of the intervention. This mapping of outcomes and experience enabled the CYP to track their own perception of benefit over time, and supported them to raise emergent issues within and outside the group, with the group facilitators.

It is not intended that routine outcomes data in this article be seen as robust measures of the impact of the group. Rather, the data is presented in this article as part of the description of the group process. These kinds of measures have been found to have strong clinical utility and to be effective in mental health evaluations but the CORS in particular has issues with a ceiling effect, and as evaluation tools were found to be susceptible to data error and data manipulation (Wolpert et al. 2015). The items on the assessment were simple, and the team provided competent translations to the main national language in each country. However, the tools were not standardised for use in these settings. In addition, resources for this project did not enable follow up with CYP after the intervention, or a comparison of their measures to a matched control group. A Wilcoxon test was run using SPSS, to determine whether the change between assessment and completion of the intervention was statistically significant. It is recognised that this is a crude measure of significance of change over time. However, this is presented in this paper not as definitive evidence of effectiveness, but to illustrate the shifts in perceived wellbeing over time as CYP move through the group intervention. All 58 CYP who participated completed CORS and GSRS questionnaires at the sessions they did attend. Only 21 CYP completed the final group measures, due to a substantial number of CYP choosing not to attend the final session of the group. In some cases, this was for reasons not related to the group (family holidays, parents' evening at school, etc.), but for some, the therapists reported that this appeared to be related to reluctance to 'say goodbye' and deal with endings in the group context.

\section{Qualitative Interviews}

At the end of the group, CYP were invited to participate in individual interviews, reflecting on their experience of the group intervention and their perception of its value and impact in their everyday life. The interviews were conducted by the independent researcher, to maintain a level of separation between the group process and the research. It had been our intention to only interview 3 children in each partner site, but group participants explained that they strongly wanted to participate, and consequently a larger group of 21 children were interviewed. (See Table 2 for a summary of evaluation participants.)

The transcribed interviews were analysed thematically (Braun and Clark 2006). Analysis was completed on transcripts that were in the original language of the interview. Two researchers coded each transcript, before coding was compared, discussed and refined. This involved a careful coding of the transcripts, attending to the content and meanings represented in the data. Coders from the various partnerships met online to discuss the coding process, and used an interrater process to refine the coding and subsequent thematization of the data. At this point, research teams in each country provided English translations for the relevant data extracts for each coded segment of each interview, and these were considered alongside relevant data from other countries to build the final themes from the coded extracts. A final check of the themes was completed at a team meeting at the end of the project, to ensure that all partners felt their data was appropriately represented. English translations were completed by a member of each national team who was fluent in English and the language of the interview, and was then cross checked by another team member fluent in both languages.

\section{Results}

\section{Analysis of Wellbeing and Group Process Measures}

In this section, CYP's mapping of their experience of the group and its impact are represented through their scores over time on CORS and CGRS. In the CORS measures, CYP were asked: "Looking back over the last week, including today, help us understand how you have been feeling by rating how well you have been doing in the following areas of your life". In Figs. 2 and 3, two individual UK participants' data is presented, showing how wellbeing scores changed across the duration of the 10 -week UK intervention programme. This is a typical pattern, generally observed across the intervention in 
Table 2 Wilcoxon signed ranks test: comparing first and last session scores on CORS and GSRS

\begin{tabular}{|c|c|c|c|c|c|}
\hline Item & & $\mathrm{N}$ & Mean rank & Z score & Significance \\
\hline \multirow[t]{4}{*}{ Personal wellbeing } & - Ranks & 0 & .00 & \multirow[t]{4}{*}{-3.426} & \multirow[t]{4}{*}{.001} \\
\hline & + Ranks & 15 & 8.00 & & \\
\hline & Ties & 7 & & & \\
\hline & Total & 22 & & & \\
\hline \multirow[t]{4}{*}{ Family and close relationships } & - Ranks & 2 & 8.25 & \multirow[t]{4}{*}{-3.012} & \multirow[t]{4}{*}{.003} \\
\hline & + Ranks & 16 & 9.66 & & \\
\hline & Ties & 3 & & & \\
\hline & Total & 21 & & & \\
\hline \multirow[t]{4}{*}{ Social relationships } & - Ranks & 3 & 6.00 & \multirow[t]{4}{*}{-2.777} & \multirow[t]{4}{*}{.005} \\
\hline & + Ranks & 14 & 9.64 & & \\
\hline & Ties & 5 & & & \\
\hline & Total & 22 & & & \\
\hline \multirow[t]{4}{*}{ Overall wellbeing } & - Ranks & 2 & 3.50 & \multirow[t]{4}{*}{-3.157} & \multirow[t]{4}{*}{.002} \\
\hline & + Ranks & 14 & 9.21 & & \\
\hline & Ties & 5 & & & \\
\hline & Total & 21 & & & \\
\hline \multirow[t]{4}{*}{ Feeling listened to } & - Ranks & 1 & 10.00 & \multirow[t]{4}{*}{-2.294} & \multirow[t]{4}{*}{.022} \\
\hline & + Ranks & 11 & 6.18 & & \\
\hline & Ties & 3 & & & \\
\hline & Total & 15 & & & \\
\hline \multirow[t]{4}{*}{ Feeling valued by the group } & - Ranks & 2 & 2.50 & \multirow[t]{4}{*}{-2.681} & \multirow[t]{4}{*}{.007} \\
\hline & + Ranks & 10 & 7.30 & & \\
\hline & Ties & 3 & & & \\
\hline & Total & 15 & & & \\
\hline \multirow[t]{4}{*}{ Rating of activities } & - Ranks & 1 & 1.50 & \multirow[t]{4}{*}{-2.959} & \multirow[t]{4}{*}{.003} \\
\hline & + Ranks & 11 & 6.95 & & \\
\hline & Ties & 3 & & & \\
\hline & Total & 15 & & & \\
\hline \multirow[t]{4}{*}{ Wellbeing total } & - Ranks & 2 & 9.00 & \multirow[t]{4}{*}{-2.174} & \multirow[t]{4}{*}{.030} \\
\hline & + Ranks & 12 & 7.25 & & \\
\hline & Ties & 1 & & & \\
\hline & Total & 15 & & & \\
\hline
\end{tabular}

all 4 countries. Subjective wellbeing is rated in roughly the middle of the scale at the beginning of the intervention, and generally improves across all domains, but there is variability in this pattern, particularly in the middle of the intervention.
For many CYP, the 'dip' in scores in the middle of the intervention tended to be related to their perception of wellbeing in the family and in other relationships. Figure 4 shows $64 \%$ of the English participants reported fluctuations in

Fig. 2 CORS scores: UK Child 5

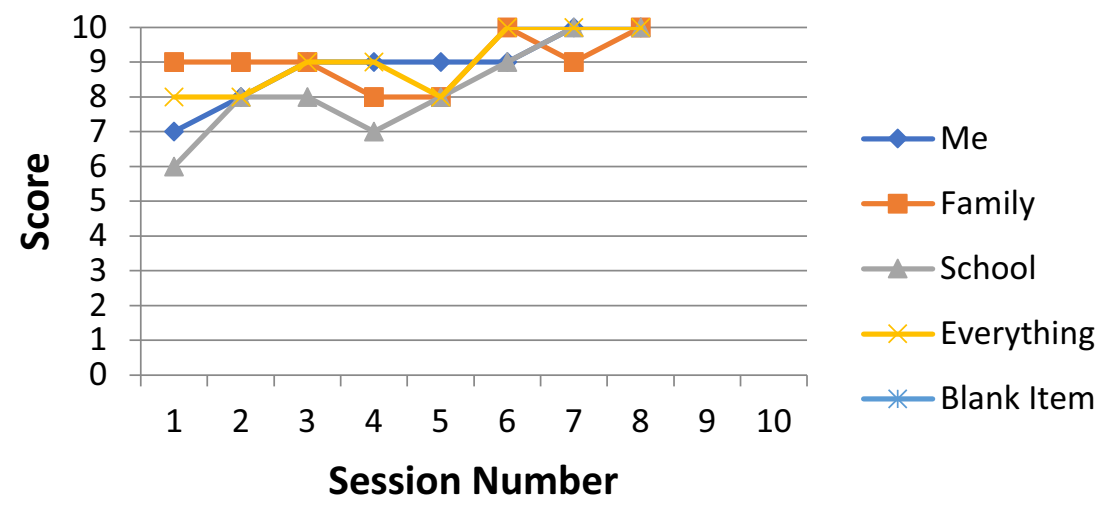


Fig. 3 CORS scores - UK Child 10

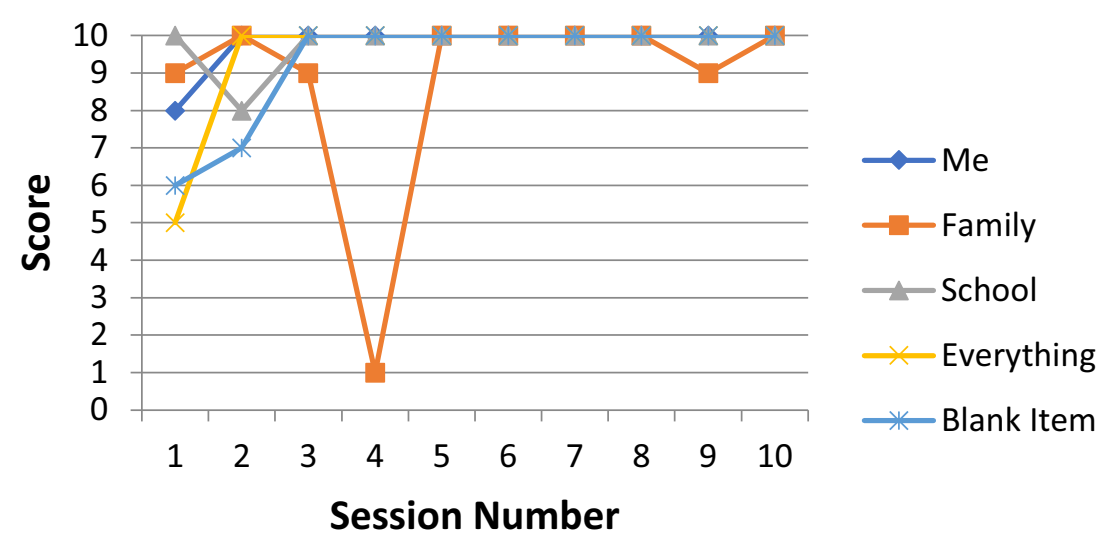

subjective 'family' wellbeing scores, with sharp troughs and peaks - also typical of the Italian and Spanish cohort data. During the programme in England, carers at times contacted facilitators, to express concerns about changes in their child's behaviour, specifically, their child's desire to talk parent who used violence. The dip in family wellbeing scores may therefore represent the difficulties CYP experienced in raising emotionally challenging material within the family, potentially unsettling the family system. This pattern varied in Greece, the intervention was conducted in a residential setting, where most participants had been removed from family of origin, or were receiving specialist day centre support from a statutory service for vulnerable families. Here participants consistently rated wellbeing highly across all domains (see Fig. 5). This may reflect the high level of additional support that CYP received in this context.

In the Child Group Session Rating Scale questionnaires (CGRS), CYP rated how they felt the group 'Listened', the 'Importance' of discussions, how they felt about 'Activities' and about each session 'Overall'. CYP in Spain and Italy (see Figs. 6 and 7) evaluated the group process positively, and the Italian data suggests a steady increase in positive appraisal over time. The sudden dip in scores for 1 individual noted in Fig. 6, and the general decrease in scores for participants in sessions 4 and 5 visible in Fig. 7 illustrate one of the advantages of session by session tracking of the group process. Although facilitators only saw anonymised data from the measures, they still could identify patterns that enabled them to monitor how the group was going, and respond. At each session, CYP were offered an opportunity to discuss their responses if they wished, opening space for reflection and feedback. By offering a relatively 'safe' way for CYP to offer regular feedback, the measures offered space for reflection, better tailoring of the intervention, and improved group cohesion. This may have contributed to the relatively low dropout rate observed for the intervention.

Tables 3 and 4 show the European quantitative pre- and postintervention evaluation data, based on the CORS and CGRS data. The output from the Wilcoxon test shows participants' positive ratings in each item outweigh negative ranks, suggesting an improvement in subjective wellbeing and perception of the group process, and these differences are statistically significant. The consistency of the difference between pre and post intervention scores is perhaps more remarkable than the significance of the difference, as it suggests that almost all CYP experienced the group and its impact as positive over time. Because there was no control group, it is impossible to comment on whether this improvement was directly related to the intervention, but it does suggest an overall positive trend, that tallies with the qualitative

Fig. 4 CORS 'Family' item - UK

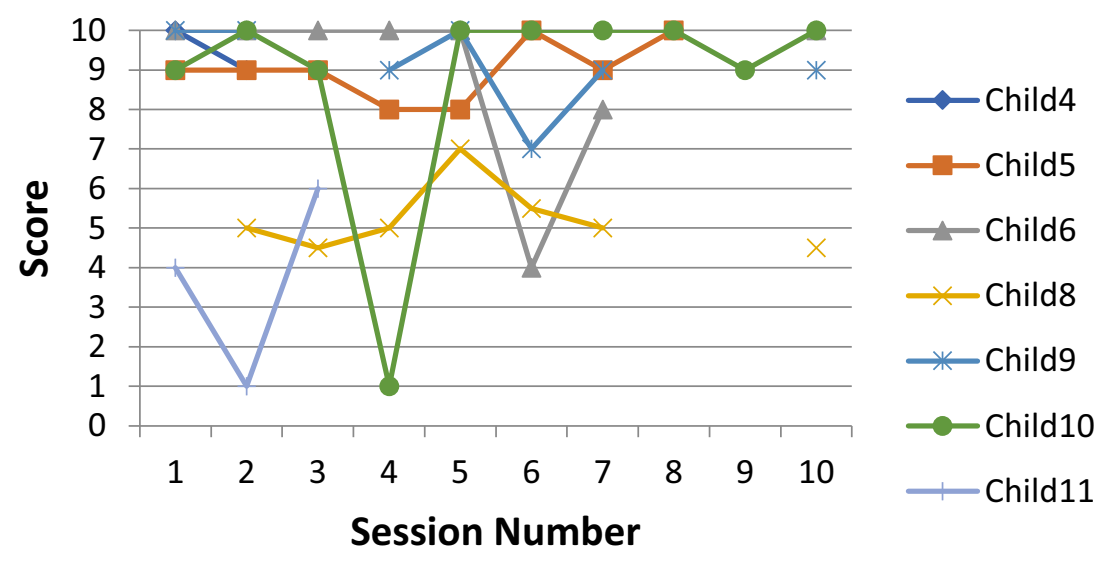


Fig. 5 Median CORS scores Greece

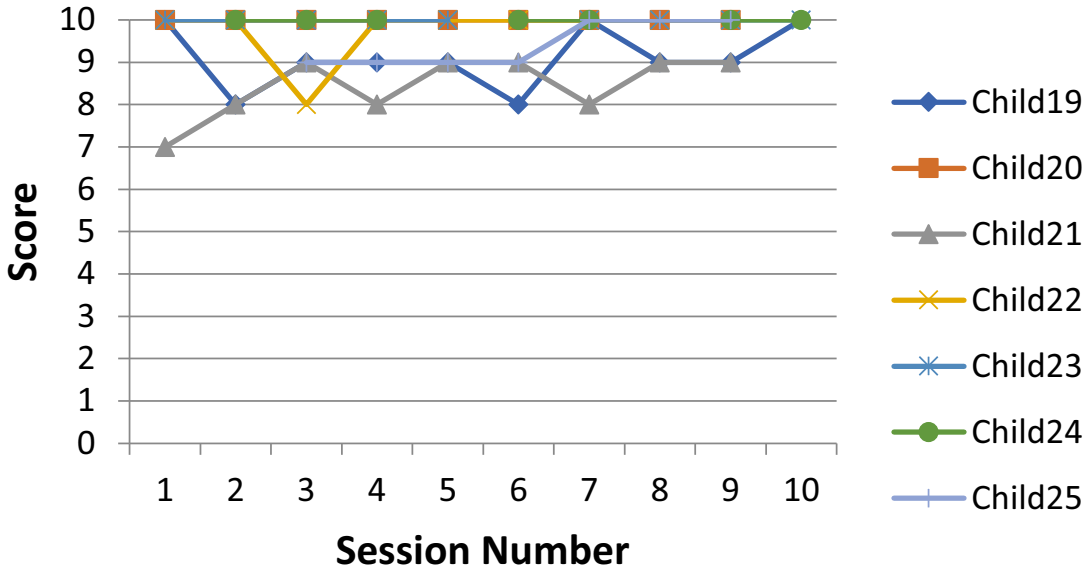

interviews completed with children. The routine outcomes data suggests that overall, participants found the group process to be a positive experience, the intervention content of value and importance, activities enjoyable and felt as though they were listened to by the facilitators and their peers.

\section{Analysis of Semi-Structured Interviews}

Three themes emerged from the thematic analysis of CYP's accounts of their experiences and perceptions of the intervention. These were "Working Together: Building Trust and Sharing Common Experiences" in which CYP reflected on the value of working in groups with other CYP who had also experienced domestic violence and abuse; "Disclosures, creativity and working with emotions", in which we explore CYP's accounts of the elements of the group that enabled them to work through complex emotions and difficult experiences; and "Roots and Branches: Working with relationships", which considers CYP's accounts of working with and transforming relational experiences.

\section{Working Together: Building Trust and Sharing Common Experiences}

One of the things CYP seemed to value most about their experiences in the group was that they shared $a$ common history with other group participants that helped them to share more freely and enabled them to feel less isolated and 'different' from other CYP. The groups were contexts of solidarity, in which CYP felt they were able to express themselves and be understood. The children reported that they felt the group was a positive context, a space that they valued and looked forward to:

Rosa (16, Spain): I truly liked it, I felt heard, because you talk about things you've lived and that others have experienced the same thing and that ... and I've never met anyone before who'd had the same family problems as me, um ... abuse... thus ... then ... is a (softly) dunno how to... like ...it has been very positive.
Fig. 6 Median CGSRS scores Spain

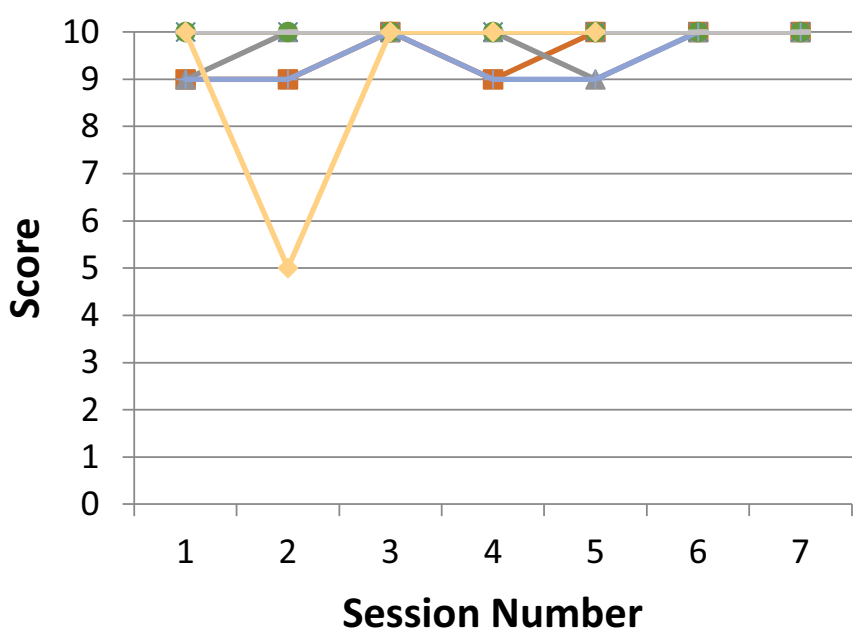


Fig. 7 Median CGSRS scores Italy

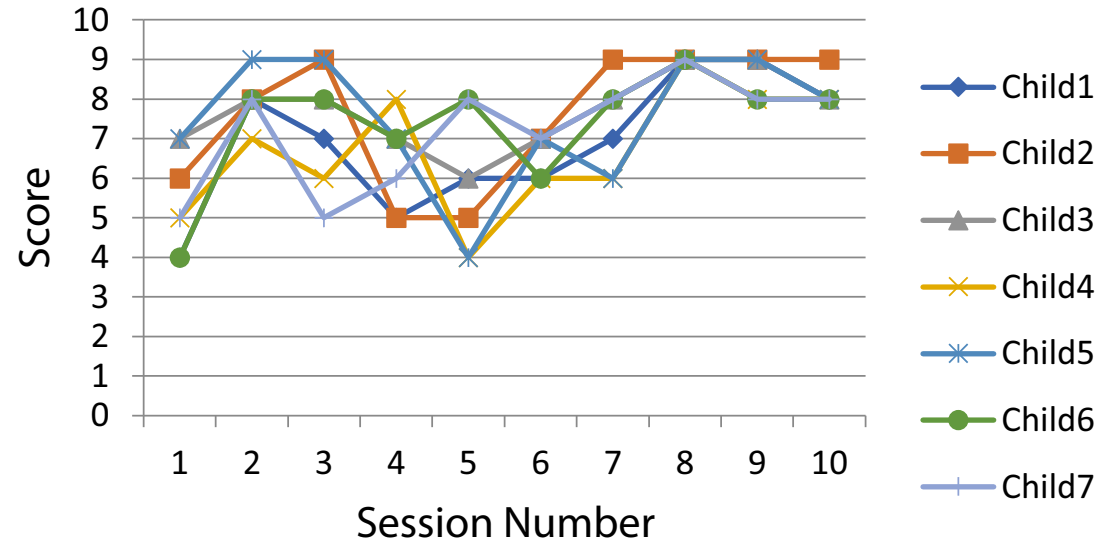

Most children commented that they had not previously understood that other children had had similar experiences, and that being in the group with other survivors of domestic violence enabled them to feel a commonality with the other children. This helped them to feel less different from other children, because of a sense of shared history. Understanding that there were others with similar experiences also enabled the children to build a stronger sense of community, which allowed for a deeper level of connection and self-expression. Shared experiences enabled children to feel less isolated and different from others, recognising that other children had experienced the same kinds of difficulties they had. Shared histories were seen as particularly powerful in one of the group activities, where participants explored some photos and stories children had shared with researchers during interviews in the first phase of the project. When asked what she had learned from the intervention, Delia (17, England) said: "That I'm not the only one who has witnessed domestic violence." Talking with CYP who shared common experiences enabled them to talk openly about their experiences, without feeling embarrassed or ashamed of what might be seen as a stigmatised experience. This community context also enabled CYP to feel more positively about themselves. They experienced not just what they could

Table 3 Children interviewed about their experiences of the group based therapeutic intervention

\begin{tabular}{llll}
\hline Location & Gender & Age range & Mean age \\
\hline England, UK & 2 boys, 4 girls & $11-17$ & 14 \\
Greece & 2 boys, 4 girls & $12-17$ & 14.5 \\
Italy & 2 girls, 2 boy & $13-18$ & 15.25 \\
Spain & 4 girls & $11-16$ & 13.5 \\
\hline
\end{tabular}

take from the group, but also what they could give to others, allowing them to have positive relational experiences.

Giorge (15, Greece): I gave good friendship, contact, good behaviour, I could be a role model to many kids. I saw many kids do this. What I gave, in general, when we talked - someone was giving advice to the other. So I am not bigging myself up. I liked that. I helped, and they helped me at that time.

The groups provided a context in which mutual support, respect and kindness was a group norm. This enabled all participants to experience the benefits of these qualities, both in themselves and others. The shared experience is seen as enabling mutual support. The CYP reported that the mutuality of experience was key to the benefits they derived from the group - that shared experience both enabled others to listen to them when they spoke, and also enabled them to support others:

Children described the group as a positive, trusting environment in which they could express themselves, build selfconfidence, and test out and strengthen their capacity to trust others. Trust was foundational to the work that children were able to do together, and was built organically. Antonia (18, Italy) notes:

I learnt to respect my self and to open up with others. I learnt to trust in myself.... The intervention made us stronger, and improved our self-confidence.

From the shared activities, and particularly shared creative activities, children built a sense of trust in each other and in the group. For instance, commenting on doing the Tree of Life activity in the group, Hannah (11, England) noted: "I learnt who I can trust". Trusting relationships were established in the group, not just through 
Table 4 Table of themes

\begin{tabular}{lll}
\hline Theme & $\begin{array}{l}\text { Number of references } \\
\text { in interviews }\end{array}$ & $\begin{array}{l}\text { Number of } \\
\text { participants }^{\mathrm{b}}\end{array}$ \\
\hline Working Together Building trust and sharing common experiences & 85 & 16 \\
Common histories & 29 & 9 \\
Positive relational experiences & 13 & 8 \\
Trust as foundational & 8 & 7 \\
Practicalities and group dynamics & 28 & 14 \\
Disclosures creativity and working with emotions & 59 & 13 \\
Space to talk & 35 & 11 \\
Working with feelings & 2 & 1 \\
Feeling empowered & 10 & 7 \\
Working creatively & 11 & 10 \\
Roots and branches Working with relationships & 54 & 20 \\
Complex family relationships & 6 & 5 \\
Relationships with father & 5 & 2 \\
Transforming relationships & 17 & 6 \\
Future orientation & 16 & 7 \\
\hline
\end{tabular}

a The number of times each theme or subtheme is referred to across all interviews

b The number of participants who referred to the theme or subtheme

explicit trust building activities but also through shared experience and communal activity. Participants suggested that trust was a key facilitator and outcome of the group process. They felt that their experiences in the group enabled them to live more trustingly outside the group.

Giorge (15, Greece): The most important thing I learnt? To trust people, as I didn't before. I was cautious. But when you get to know someone and they trust you, you can test that out. And this is the most important thing for me, trust.

Through trusting others within the group, Giorge learned important skills that he can apply beyond the group. This included an ability to trust consciously, but not unthinkingly, as he recognised that trust emerges in relationships as you get to know someone; people should be allowed to demonstrate their trustworthiness in relationships.

In some groups, there was a strongly expressed wish for this sense of community to extend beyond the therapeutic context, for example Rosaria (18, Italy): I would have loved to go out with the others... For instance, to go to the sea. This suggests that the intervention provided CYP with a supportive context, and a sense of community, that they wished could be extended beyond the intervention context. Many participants reported that they wanted more time in the group. Giorge made a particularly poignant point that the number of sessions was enough to produce a sense of bonding in the group, but not enough for them to sustain the relationships formed there.

We are emotionally tied together, psychologists, children. Most of us, all of us were moved at the last session... hugs, kisses, saying goodbye... I would say that if it could last longer, then we could manage on our own. Now we know the way.

The sense of not having enough time did seem to be a reflection of both how positively the group was regarded, the value CYP felt in the relationships they built in the group, and a sense of needing more space and time to process issues that emerged there.

\section{Disclosures, Creativity and Working with Emotions}

Being in a trusting environment enabled participants to express themselves, and to disclose things that they had not previously felt able to discuss. For example, Ruby (11, England) said: "The first time I was a bit scared and talking about the bullying ... So Penny (facilitator) helped me say what happened." The group and the facilitator were able to provide a safe space to talk about current experiences of violence and coercion (bullying) that were troubling her. Sharing in the group was also experienced as liberating: 
Ruby (11, England): It feels like how I feel and that I don't have to be afraid any more. (Int: Afraid of what?) Ruby: Talking. I can speak more about what I want to do, and so I don't feel trapped inside anymore ... I think that I'm more confident around people now. Before I wouldn't talk, nobody really knew anything about me. But now I actually like talk to people and show them how much I talk and the stuff I like and stuff

She suggests here that speaking out built her confidence, and had a significant knock on effect for the way that she saw herself generally, undermining her negative self-image, and enabling her to question her acceptance of other people's negative comments about her.

Although CYP felt it was important to be able to disclose, it was also important that they did not feel pressured to talk in the group:

Eugenia (14, Greece): Most times we didn't talk about the things we didn't want, and we didn't feel the pressure to do so.

The non-directive, facilitative approach of the group, and the lack of a strict, overly manualised format provided space for them to discuss issues that mattered to them. This is a marked difference between the MPOWER programme and many manualised programmes for CYP working with the experience of domestic violence and abuse. The programme suggests themes and activities for sessions, but these are used flexibly, and the session focus is agreed with CYP at each session. CYP described this as central to the group's success, enabling them to see the group as a safe space. The ability to decide when and how to speak about experiences is also an important element of personal boundary maintenance, and a key component of effective self-expression.

This trusting space does not need to always be serious rather the children often used the term 'fun' to describe their experiences of the group.

Hannah (11, England): Sometimes during the sessions they will say something and then one of the staff or one of the children would start making a couple of jokes so it doesn't get too uncomfortable, and we'll have a laugh and then we'll go back to it.

Hannah suggested here that interspersing of difficult, more serious subjects with humour, was used intuitively in the group as a way of managing difficult emotion. This helped to diffuse tension and discomfort, enabling an interlude before more serious discussion is restored.
Of course, humour can also be used defensively, as a means of deflecting focus away from painful and difficult issues.

Kevin (13.England) Things like when things are awkward I used to sometimes try and mess about and make it a bit funny to help me cope. Personal things that I don't really want to talk about and so I try and avoid answering the questions.

Through his participation in the group, Kevin has become aware of his use of humour as a defence, and has understood that he uses this as a strategy to avoid talking about difficult experiences. He later notes that this is also part of the way he tries to support other people, by lightening the mood and trying to cheer them up when he feels down: "I've learned more about how I make people feel and what reaction I have on people." This is a very positive reframing of what is a very common form of coping for boys who experience violence - the tendency to be the 'class clown', something that is often problematically labelled as disruptive or negative behaviour in schools for instance. Through the group, Kevin has identified his use of this strategy as a defence against difficult his and others' feelings, and has been able to re-work it (also) as a positive aspect of his self.

In our first phase interviews with CYP, creative methods were seen as very powerful in exploring challenging issues around domestic abuse (See Callaghan and Alexander 2015, 2017a; Fellin et al. 2018b). Children also told us in phase one that they used embodied strategies to maintain a sense of agency and coping (Alexander et al. 2016, Callaghan et al. 2017a; Fellin et al. 2018b). For these reasons creative methods (drawing, music, and drama therapy techniques) were used in the intervention. These were highly valued by participants in all four countries:

Antonia (18, Italy): I loved when at the beginning of each session we listened to and danced with the music we could choose

Ruby (11, England): Drawing and talking about our feelings and things, that made me a bit happier.

The physical and expressive aspects of the group were also valued by CYP who were restless and physically agitated (a common response to experiences of domestic abuse) (Graham-Bermann and Seng 2005; Szymanski et al. 2011). As Kevin (13, England) said: "Because I don't like sitting still.”

These methods were also valued as a means of expressing experiences that were difficult to articulate, and as a vehicle for emotional catharsis and working with feelings, and for understanding the spatial and embodied aspects of their experiences of violence and recovery from violence. Talking about an activity in which participants were encouraged to explore 
their use of space, and their sense of personal space, Giorge (Greece) notes:

It had some meaning because I could see what my limits were and probably how they will be forever, because I don't think they will change.

The activity helped Giorge understand his experience of interpersonal space and how that might shape future social interactions.

Creative techniques in the group enabled CYP to safely explore their experiences of embodied emotion, enabling a space for them to express and begin to name difficult emotional experience:

Hannah (11, England): There was a sheet and it had a man drawn on it and we had to write good and bad feelings we've had... Sometimes when I get really upset it feels like my belly is going to burst open - I drew that. That's what we do, it's quite fun.

One of the things that is perhaps remarkable about Hannah's statement here is that, while she was describing a very challenging, difficult emotional experience that clearly is painful for her, the safe space of the group and the creative experience enabled this to be a non-threatening experience for her - one she is in retrospect able to label as 'fun'. She later comments on this activity again:

My most favourite was the person, because when we did the feelings we understood how they felt and if they were ever feeling like that again, we know how to comfort them and stuff. If I've got that pain again, they know how to comfort me.

In the shared creative experience she has acquired a profound understanding of the feelings she has, which had previously been unnamed and unarticulated. Now she is able to both recognise the feeling, and soothe herself. She returns to this concern when discussing her experience of anger, as something uncontrollable, explosive, that made her feel pulled apart ("it feels like my mind's blowing up and let's just say it feels like I've been chopped into cubes, glued back together and been blown up"). Being able to put this into such evocative words was something she found helpful:

Yeah it's actually helped me be calmer. I've still got the strength on me, but it's sort of weakened it just a tiny bit, so I can hold it in more and not have to let it all out.

Creative activities have enabled her to express her anger in a more contained and safe way, enabling her to gain insight and perspective, seeing her 'strength' as something she has more control over - she is 'calmer', less violent. Being 'calmer' does not undermine her sense of personal strength, but she feels less compelled to express it explosively.

Rosa (16, Spain): We brought pictures, and each one expressed what happened to you in your past. You remember and you realize, for example, what you should have done to get out of this, how you might have fixed it but were blocked. I didn't know how to react, and now from coming here, now I know not to shut things up.

Rosa found that talking through the photos she brought to group enabled her to work out that she could have 'fixed' things if she had been enabled, but that the family circumstances prevented this. She recognises that she now has a different set of strategies, ones that enable her to express her feelings and not be silenced.

\section{Roots and Branches: Working with Relationships}

Some activities were designed to enable CYP to visualise and work through their family experiences - for example, the 'tree of life' (Ncube 2006), family sculpture (Duhl et al. 1973) and ecomaps (Hartman 1979) or family drawings. These were particularly highly valued by participants. For example, Martina (14, Spain) said "the tree seemed...like you came out from a past ... Dunno, I liked it... because you can tell a story in a picture ..." These visual and spatial representations of family helped CYP connect their past to their present and future, and to express experiences of complex and conflicted family relationships they might otherwise have found hard to put into words.

Relationships were described as both a source of considerable strength for CYP, and a source of conflict, complexity and challenge. For example, being positioned as a 'carer' enabled CYP to feel powerful, capable, kind - all contributing to a positive sense of self. Children suggested the groups helped them to develop a better understanding of domestic violence itself, and its impact on family relationships.

Hannah (11, England): Because now I know how mum was feeling and now I can support her more... Yeah because now I know what she's been doing, how she feels and how to solve fights and arguments, to keep her calm.

Hannah saw her group-learning as having a positive impact on her relationship with her mother, who she feels she now understands better. By gaining better insight into her own feelings of anger, and the way that these are in turn shaped by her experiences of violence, she is able to extend those insights to her relationship with her mother. Hannah describes herself engaged in what other authors have described as problematic 
parentified behaviour (Katz 2015) - caregiving for her mother, looking after her feelings. But Hannah clearly derives a sense of competence from her ability to understand her mother's responses, and it may be that supporting CYP to think flexibly about their often positive, empowered experience of self-as carer might be more useful in intervention than dismissing it as premature or pathological. Here, Hannah presents herself as a partner with her mother, managing difficult feelings together, in alliance, suggesting this might be a potential route for building a sense of emotional competence.

Positions in the family could also unsettle CYP. The paradoxes of role inversions, being 'friends' or carers to siblings and to the non-violent adult, as well as familial alliances, conflicted loyalties, and familial fractures and feuds, also required attention and consideration in the groups. The group based activities and discussions helped CYP have a better understanding of the broader relational impact of domestic abuse. This included an understanding of the limits of their own responsibilities and what they should do in relation to preventing violence.

One source of considerable challenge for CYP was their often ambivalent relationship with the perpetrator, who was often their father. In many families, and in the services that CYP had used, the perpetrator was often represented in very absolute and polarised ways, as entirely bad. In some families the perpetrator had become an unspeakable entity, making it difficult for CYP to talk through their relationships with them:

Ruby (11, England): It (the group) makes me more confident. Like I aim and talk to my mum more, but we don't really talk about him in the house because my brothers don't like him.

This can produce challenges for CYP in establishing realistic images of their perpetrator fathers (or stepfathers), or of integrating more positive relational experiences of their fathers with a recognition of their negative behaviour. For instance, Ruby had started to idealise her father, craving contact. The group provided a space in which Ruby could start to speak about her ambivalent feelings about her father. Ruby used resources she learned in the group - particularly the drawings and other creative activities produced in the group - to 'take home' these messages to her family. This was not an easy process, and it is important to recognise that the desire to see the father is rooted in idealisation and may not be a realistic or safe desire to indulge. But by retaining silence around him, the family dynamic was encouraging rather than dealing with her perception of his place in her life, and of his absence.

CYP also described their anxiety about becoming the perpetrator, taking on the violent (step)parent's aggression, relational challenges and irrationality. Given the popularity of the discourse of intergenerational transmission in professional work with families affected by domestic violence, this anxiety about learning the perpetrator's behaviours is often entrenched by well-meaning professionals. This is further underscored by a service model that, when it does concern itself with children, tends to emphasise managing their problem behaviours, a model that is dependent on a view of children as passive recipients of environmental learning. For many CYP, the complexity of family life hinged around (perpetrator) fathers. For instance Leo (17, England UK) said:

I did because I used to have anger issues, and my dad did to an extent, and I was worried that maybe in an argument I would just snap and I would just start shouting or maybe start hurting maybe my own kid or someone else.

Leo found space within the group to express his anxieties about 'intergenerational transmission', about growing up to be like his father, and also to work through those anxieties. For many of the boys, this was expressed as a worry about being a bad parent:

I think we were discussing about how maybe I don't want kids or maybe how I don't want this, because I don't want to turn out like my mum or my dad. And they kind of say to you, "Look, you can grow strong enough to grow away from that. You're a good person and you're a better person than that." ... The other day they said, "Look, you'd be a brilliant dad," or this and that, "because of your personality." And maybe if you do feel like you've got some of your dad in you or some of your mum in you, then you can break away from that because, by doing that and knowing what's wrong, you know what's right.

By recognising positive qualities that were different from the perpetrator, the group reassured Leo, and helped him to begin to envision an alternative positive future for himself.

This sense of the father as an unspeakable within the family was particularly problematic for some children, for whom the violent parent became larger than life, or for whom the positive elements of their relationship with the violent parents became inexpressible. The need to recognise both the positive and negative aspects of historical relationships with perpetrator parents was discussed at length, particularly in the English groups. This was not always straightforward - for instance, Leo says:

So in a way, my dad's wrongdoing has done a lot of right, but at a sacrifice. So as much as I want to drink and explore as a teenager and a young adult, when you grow up you kind of realise what damage it does, not only to your personal health but your actual mental health and what you can do to other people. 
By talking through the problematic aspects of his relationships with his father, and working through is experiences with him, Leo is able to find ways of incorporating these positively into his sense of who he is - and who he is not. This enabled the emergence of a more realistic and optimistic future orientation for himself. Many of the CYP we spoke to shared Leo's anxieties about being doomed to repeat the cycles of violence and abuse to which they had been exposed. This is a significant discourse in circulation in professional, academic and popular representations of children who experience domestic violence, and it is particularly important that many CYP felt that they had shifted their perspective on this, and had, through the intervention, been able to forge a more positive vision of their future selves.

\section{Future Orientation}

The creative and systemic methods used in the group both explicitly and implicitly supported CYP to reframe and retell their stories, to change the endings, to play with different plots and different outcomes. This structure enables children to challenge a sense of themselves often articulated in domestic violence services and literature, that they are doomed to follow one plot line - the repetition of violence and conflict.

Rosaria (18, Italy): I learned that anything that happens in our lives, even bad things, can be transformed.

Here, Rosaria articulates the possibility of transformation, which she is not doomed to repeat. Giorge (15, Greece) also highlighted this sense of new possibilities:

The facilitator asked us to imagine our life in 10 years. And we closed our eyes and thought about how we would be. I thought of a profession and finding my wife. My children, my home. I had an imaginary world in my mind and it was very nice, I was relaxed. How nice if the future was like that. Now it's still early, I can make my future, I have enough time. I have more optimism for the future than I did before.

He envisions himself not just successful in the world of work, but also as relationally competent, happy and settled. He ascribes this to a sense of fresh hope that he had built in the group intervention context - a new optimism that a better future was possible for himself. In addition to this focus on the distant future, children also reflected on the changes that they have been able to make in the present and near future, and how this will help them build towards a positive adulthood:

Rosa (Spain): Cos you express yourself, and you think about your future, your past and your present ... and that normally you do not stop to think about all that, your dreams, your skills ... how you are too, it helps to know yourself inside.

Arturo (13, Italy): Because it helps to cope with these moments and to move forward.

For many people's experiences of trauma produce a sense of a foreshortened future - of living only for today (American Psychiatric Association 2013). Ratcliffe et al. (2014, p. 2) suggest this sense of foreshortened future involves "a sense that the future is bereft of positive, meaningful life events is equally a sense that one's meaningful life is in the past, finished." Adding to this the anxiety children felt about being doomed to repeat cycles of violence, and it is clear that this shift in their feelings about 'tomorrow' is an important one. Leo very eloquently articulates how the integration of familial experiences into his sense of self enables the development of this more positive sense of his future:

Leo : we did do a bit of activity where we did the tree of life... where you discuss your roots and then what your main things are, your trunks, and then your branches off and your fruits, your dreams and that. So that helps you think ahead and think about what you really want to be. It made you really realise what you've got and what you want ... So when you talk about the tree of life, you're trying not to forget where you come from. So when you talk about your roots and talk about your family and who's helped you and who's been there in your dark times and your good times, by doing that you can also talk about who you've got right now and where you want to go after, just in case, because the branches identify different paths if you don't make it. So if I don't make it as a footballer, I've always wanted to be into sports science at university. And if I don't do that, I want to be maybe an artist or an architect. So you can just aspire and you can also discover your other interests and see if they'll ever take you somewhere.

Like almost any bright, capable teenager, Leo describes a sense of his future where his world is his oyster. This is rooted in a sense of his family where he is no longer doomed to repeat familial patterns, but is able to take strength from and learn from his history, and use it - even the broken and painful bits to build a sense of his future.

\section{Discussion and Conclusions}

The article offers a contribution to a limited evaluation literature on interventions with CYP affected by domestic violence and abuse (MacMillan et al. 2016). The intervention was resource oriented, focused on recognising and enhancing the skills CYP had developed in the context of domestic violence and abuse 
(Fellin et al. 2018a). It focused on supporting CYP to express their experiences of domestic violence and abuse, and to build on their existing strengths to increase their capacity for resilience, resistance and agency. The intervention was loosely manualised, to enable it to be used flexibly with different participants, in different contexts. The intervention was used successfully in all four countries, where children who participated in the intervention reported that they felt it helped them to normalise their experiences, recognise their abilities, and find support through other people. The creative, embodied methods and relational / systemic focus (Cook et al. 2005; Vetere and Cooper 2017; White 2004), coupled with being with other CYP who shared similar experiences, enabled them to express things that they had not previously disclosed, or perhaps even recognised themselves. This was highly valued by CYP.

While the intervention involved direct work with CYP, it also enabled them to consider family relationships, and to reconfigure their sense of their relationships with others. Routine outcomes scores suggested a steady increase in subjective wellbeing as CYP engaged with the group, as well as increased positive evaluation of the group itself. This was also supported by interviews with CYP, who reported that they experienced the group as a positive, supportive and transformative space. This suggests that group based, resource oriented intervention using creative and relational methods is an acceptable and appropriate intervention for CYP of this age group (11-18 years), and that the intervention holds promise as a potentially effective way of working with CYP effected by domestic abuse.

\section{Limitations}

The study was limited by a number of factors. Although quantitative measures of subjective wellbeing were taken at the beginning and end of the intervention, practical limitations meant that it was not possible to set up a control group or to follow up at a later date to consider whether wellbeing gains were maintained. Such methods would have enabled firmer conclusions about the effectiveness of the intervention, and its impact over time. Although CYP were all invited to participate in the interviews, respondents were all CYP who had remained in the intervention. The number of CYP who dropped out was small, but it would nonetheless have been useful to understand their perspectives on the group, and to understand what might have made it more useful to them. Further, it would be useful to capture facilitator perspectives on what was successful in the groups. This was done informally, but it would be useful in future evaluations to include interviewers with facilitators. Because the delivery team came from a large range of backgrounds, and the sample size is small, it is also not possible to draw conclusions about whether facilitator characteristics played a role in determining the outcomes of the intervention.

\section{Recommendations for Research and Practice}

The MPOWER group intervention offers some interesting variations from established manualised domestic violence and abuse interventions, which were valued by the CYP who were interviewed. The flexibility of the programme, and its ability to be adapted in collaboration with CYP was particularly valued and offers a significant variation from most manualised programmes in this field. In addition, the emphasis on creative and embodied / movement based methods to support the articulation of complex experience was highly valued. These are fruitful areas for consideration in the future development of interventions for CYP affected by domestic violence and abuse. Literature on interventions in this arena is limited, and there is an urgent need for high quality research that measures the effectiveness of different interventions in a robust manner, and establishes their impact over time. This is an important recommendation for future research, and should be a priority in intervention and implementation research.

Open Access This article is distributed under the terms of the Creative Commons Attribution 4.0 International License (http:// creativecommons.org/licenses/by/4.0/), which permits unrestricted use, distribution, and reproduction in any medium, provided you give appropriate credit to the original author(s) and the source, provide a link to the Creative Commons license, and indicate if changes were made.

Publisher's Note Springer Nature remains neutral with regard to jurisdictional claims in published maps and institutional affiliations.

\section{References}

American Psychiatric Association. (2013). Diagnostic and statistical manual of mental disorders. Arlington: American Psychological Association. https://doi.org/10.1176/appi.books.9780890425596.744053.

Braun, V., \& Clark, V. (2006). Using thematic analysis in psychology. Qualitative Research in Psychology, 3(2), 77-101.

Bunston, W., Pavlidis, T., \& Cartwright, P. (2016). Children, family violence and group work: Some Do's and Don'ts in running therapeutic groups with children affected by family violence. Journal of Family Violence, 31(1), 85-94. https://doi.org/10.1007/s10896-015-9739-1.

CAADA. (2014). In plain sight : The evidence from children domestic abuse (Research Report). Cardiff: CAADA.

Callaghan, J. E. M., \& Alexander, J. H. (2015). Understanding agency and resistance strategies: children's experiences of domestic violence report. Northampton. Retrieved from www.unars.co.uk. Accessed 8 June 2018.

Callaghan, J. E. M., Alexander, J. H., \& Fellin, L. C. (2016a). Children's embodied experiences of living with domestic violence: I'd go into my panic, and shake, really bad. Subjectivity, 9(4), 399-419. https:// doi.org/10.1057/s41286-016-0011-9.

Callaghan, J. E. M., Alexander, J. H., Sixsmith, J., \& Fellin, L. C. (2016b). Children's experiences of domestic violence and abuse: Siblings' accounts of relational coping. Clinical Child Psychology and Psychiatry, 21(4), 649-668. https://doi.org/10.1177/ 1359104515620250.

Callaghan, J. E. M., Fellin, L. C., Alexander, J. H., Mavrou, S., \& Papathanasiou, M. (2017a). Children and domestic violence: 
Emotional competencies in embodied and relational contexts. Psychology of Violence, 7(3), 333-342. https://doi.org/10.1037/ vio0000108.

Callaghan, J. E. M., Fellin, L. C., Mavrou, S., Alexander, J. H., \& Sixsmith, J. (2017b). The management of disclosure in children's accounts of domestic violence: practices of telling, and not telling. Journal of Child and Family Studies, 26(12), 3370-3387. https:// doi.org/10.1007/s10826-017-0832-3.

Campo, M., Kaspiew, R., Moore, S., Tayton, S., Services, N. S. W. D. of F. and C, \& Studies, A. I. of F (2014). Children affected by domestic and family violence: review of domestic and family violence prevention, early intervention and response services. Melbourne. Retrieved from https://search.ebscohost.com/login.aspx?direct=true $\& \mathrm{db}=$ edsacd\&AN=edsacd.69366\&site=eds-live. Accessed 8 June 2018.

Cook, A., Spinazzola, J., Ford, J., Lanktree, C., Blaustein, M., Cloitre, M., .. Van Der Kolk, B. (2005). Complex trauma in children and adolescents. Psychiatric Annals, 35(5): 390-398.

Cornelius, T. L., \& Resseguie, N. (2007). Primary and secondary prevention programs for dating violence: A review of the literature. Aggression and Violent Behavior, 12(3), 364-375. https://doi.org/ 10.1016/j.avb.2006.09.006.

Duhl, F., Kantor, D., \& Duhl, B. (1973). Learning space, and action in family therapy: A primer of sculpture. Seminars in Psychiatry, 5(2), 167-183.

Duncan, B., Miller, S., Sparks, J., Claud, D., Reynolds, L., Brown, J., \& Johnson, L. (2003). The session rating scale: Preliminary psychometric properties of a "working" alliance measure. Journal of Brief Therapy, 3, 3-12.

Fellin, L. C., Callaghan, J. E. M., Alexander, J. H., Papathanasio, M., Harrison-Breed, C., \& Mavrou, S. (2018). Empowering young people who experienced domestic violence and abuse: the development of a group therapy intervention. Clinical Child Psychology \& Psychiatry, accepted.

Fellin, L. C., Callaghan, J. E. M., Alexander, J. H., Mavrou, S., \& Harrison-Breed, C. (2018b). Child's play? children and young people's resistances to domestic violence and abuse. Children \& Society. https://doi.org/10.1111/chso.12302

Fergusson, D. M., Horwood, J., \& Ridder, E. M. (2005). Partner violence and mental health outcomes in a New Zealand birth cohort. Journal of Marriage and Family, 67(December), 1103-1119.

Fujiwara, T., Okuyama, M., \& Izumi, M. (2012). The impact of childhood abuse history, domestic violence and mental health symptoms on parenting behaviour among mothers in Japan. Child: Care, Health and Development, 38(4), 530-537. https://doi.org/10.1111/j.13652214.2011.01272.x.

Glodich, A., \& Allen, J. G. (1998). Adolescents exposed to violence and abuse : A review of the group therapy literature with an emphasis on preventing trauma reenactment. Journal of Child and Adolescent Group Therapy, 8(3), 135-154.

Graham-Bermann, S. a., \& Seng, J. (2005). Violence exposure and traumatic stress symptoms as additional predictors of health problems in high-risk children. The Journal of Pediatrics, 146(3), 349-354. https://doi.org/10.1016/j.jpeds.2004.10.065.

Hartman, A. (1979). Finding families: An ecological approach to family assessment in adoption: A project craft publication. London: Sage.

Howarth, E., Moore, T. H., Welton, N. J., Lewis, N., Stanley, N., MacMillan, H., Shaw, A., Hester, M., Bryden, P., \& Feder, G. (2016). IMPRoving outcomes for children exposed to domestic ViolencE (IMPROVE): An evidence synthesis. Public Health Research, 4(10), 1-342. https://doi.org/10.3310/phr04100.

Humphreys, C. (2006). "Talking to my mum": Developing communication between mothers and children in the aftermath of domestic violence. Journal of Social Work, 6(1), 53-63. https://doi.org/10. 1177/1468017306062223.

Hunt, T. K. A., Slack, K. S., \& Berger, L. M. (2017). Adverse childhood experiences and behavioral problems in middle childhood. Child
Abuse and Neglect, 67, 391-402. https://doi.org/10.1016/j.chiabu. 2016.11.005.

Jenney, A., \& Alaggia, R. (2012). Children's exposure to domestic violence: integrating policy, research, and practice to address children's mental health. In R. Alaggia \& C. Vine (Eds.), Cruel but not Unusual: Violence in Canadian Families (2nd ed.). Waterloo: Wilfrid Laurier University Press.

Katz, E. (2015). Domestic violence, Children's agency and mother-child relationships: Towards a more advanced model. Children \& Society, 29(1), 69-79. https://doi.org/10.1111/chso.12023.

Lacasa, F., Álvarez, M., Navarro, M.-Á., Richart, M.-T., San, L., \& Ortiz, E.-M. (2016). Emotion regulation and interpersonal group therapy for children and adolescents witnessing domestic violence: A preliminary uncontrolled trial. Journal of Child \& Adolescent Trauma, 2009. https://doi.org/10.1007/s40653-016-0126-8.

MacMillan, H., Howarth, E., Moore, T. H. M., Welton, N. J., Lewis, N., \& Stanley, N. (2016). IMPRoving outcomes for children exposed to domestic ViolencE (IMPROVE): An evidence synthesis. Public Health Research, 4(10).

Masten, A. S., Cutuli, J. J., Herbers, J. E., \& Reed, M. J. (2009). Resilience in development. In Oxford handbook of positive psychology (pp. 117-131). New York: Oxford University Press.

McFarlane, J., Fredland, N. M., Symes, L., Zhou, W., Jouriles, E. N., Dutton, M. A., \& Greeley, C. S. (2017). The intergenerational impact of intimate partner violence against mothers on child functioning over four years. Journal of Family Violence, 32(7), 645-655. https://doi.org/10.1007/s10896-017-9913-8.

Meltzer, H., Doos, L., Vostanis, P., Ford, T., \& Goodman, R. (2009). The mental health of children who witness domestic violence. Child \& Family Social Work, 14(4), 491-501. https://doi.org/10.1111/j.13652206.2009.00633.x.

Ncube, N. (2006). The tree of life project. Of Narrative Therapy \& Community Work, 1, 3-16.

Peled, E., \& Davis, D. (1995). Groupwork with children of battered women: A Practitioner's manual (interpersonal violence: The practice series). Thousand Oaks: Sage.

Perry, B. D. (2014). Creative interventions with traumatized children. Surrey: Guilford Publications.

Peterson, S. M., \& Yates, T. M. (2013). Early childhood relationships and the roots of resilience. In Encyclopedia on early childhood development (pp. 1-6). Montreal: CEECD.

Ratcliffe, M., Ruddell, M., \& Smith, B. (2014). What is a sense of foreshortened future? A phenomenological study of trauma, trust, and time. Frontiers in Psychology, 5(September), 1-11. https://doi.org/10.3389/fpsyg.2014.01026.

Roseby, V., Johnston, J., Gentner, B., \& Moore, E. (2005). A safe place to grow - A group treatment manual for children in conflicted, violent, and separating homes. New York: The Haworth Press.

Sharp, C., Jones, J., Netto, G., \& Humphries, C. (2011). We thought they didn't see: Cedar in Scotland - children and mothers experiencing domestic abuse recovery evaluation report. Retrieved from https:// www.cedarnetwork.org.uk/wp-content/uploads/2011/03/ Evaluation-Report-DOWNLOAD1.pdf. Accessed 3 June 2018.

Siegel, J. P. (2013). Breaking the links in intergenerational violence: An emotional regulation perspective. Family Process, 52(2), 163-178. https://doi.org/10.1111/famp.12023.

Smith, E. (2016). Domestic abuse, recovering together. Leicester.

Stanley, N., Miller, P., \& Richardson Foster, H. (2012). Engaging with children's and parents' perspectives on domestic violence. Child \& Family Social Work, 17(2), 192-201. https://doi.org/10.1111/j.13652206.2012.00832.x.

Szymanski, K., Sapanski, L., \& Conway, F. (2011). Trauma and ADHDAssociation or diagnostic confusion? A clinical perspective. Journal of Infant, Child, and Adolescent Psychotherapy, 10(1), 51-59. https://doi.org/10.1080/15289168.2011.575704. 
Tjersland, O. A. (2012). A process study of group therapy with children who have been. FOKUS PA FAMILIEN, 1, 6-26.

Ungar, M. (2011). Community resilience for youth and families: Facilitative physical and social capital in contexts of adversity. Children and Youth Services Review, 33(9), 1742-1748. https:// doi.org/10.1016/j.childyouth.2011.04.027.

Vetere, A., \& Cooper, J. (2017). Children who witness violence at home. In A. Vetere \& E. Dowling (Eds.), Narrative therapies with children and their families: A Practitioner's guide to concepts and approaches (2nd ed.). London: Routledge.

Walsh, F. (2003). Family resilience: A framework for clinical practice. Family Process, 42(I), 1-18. https://doi.org/10.1111/j.1545-5300. 2003.00001.x.

Walsh, F. (2015). Strengthening family resilience. Guilford: Guilford Publications.

White, M. (2004). Working with people who are suffering the consequences of multiple trauma: A narrative perspective. The International Journal of Narrative Therapy and Community Work, $1,45-76$.
White, M., \& Morgan, A. (Eds.). (2006). Narrative therapy with children and their families. Adelaide: Dulwich Centre Publications.

Wolpert, M., Cheng, H., \& Deighton, J. (2015). Measurement issues: Review of four patient reported outcome measures: SDQ, RCADS, C/ORS and GBO - their strengths and limitations for clinical use and service evaluation. Child and Adolescent Mental Health, 20(1), 63-70. https://doi.org/10.1111/camh.12065.

Wood, S. L., \& Sommers, M. S. (2011). Consequences of intimate partner violence on child witnesses: a systematic review of the literature. Journal of Child and Adolescent Psychiatric Nursing : Official Publication of the Association of Child and Adolescent Psychiatric Nurses, Inc, 24(4), 223-236. https://doi.org/10.1111/j.1744-6171. 2011.00302.x.

Zahradnik, M., Stewart, S. H., O’Connor, R. M., Stevens, D., Ungar, M., \& Wekerle, C. (2009). Resilience Moderates the Relationship Between Exposure to Violence and Posttraumatic Reexperiencing in Mi'kmaq Youth. International Journal of Mental Health and Addiction, 8(2), 408-420. https://doi.org/10.1007/s11469-0099228-y. 